\title{
SELF-ESTEEM AS A PREDICTOR OF PSYCHOLOGICAL ADJUSTMENT TO LIMB LOSS: A CASE STUDY OF ACQUIRED LIMB AMPUTATION
}

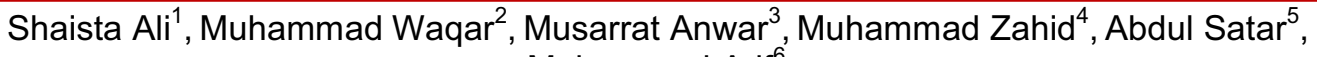 \\ Muhammad Arif ${ }^{6}$
}

\section{ABSTRACT: \\ OBJECTIVES:}

To examine the psychological issues following acquired limb amputation and examine the significance of positive self-esteem in the psychological adjustment of amputation.

\section{METHODOLOGY:}

This case study was conducted in the surgical and orthopedic units of different government and private hospitals of Peshawar district. The study includes a sample of 100 acquired limb amputees, both adult males and females admitted in different hospitals of Peshawar. Patients with congenital limb loss or with preexisting psychological issues were excluded from the study. Psychological adjustment scale developed by Sabir (1999) and Self-Esteem scale developed by Rifai's (1999) was used to determine the amputee's level of psychological adjustment and self-esteem.

\section{RESULTS:}

Results revealed that amputation leads to number of psychological issues. It was found that males had lowered self-esteem and severe adjustment issues then females while young amputees exhibit greater signs of maladjustment as compared to older amputees. Regression analysis for selfesteem predicting psychological adjustment also displayed pronounced differences in the level of psychological adjustment due changing level of self-esteem. The model suggested a strong positive relation between self-esteem and psychological adjustment $(r=0.880, B=0.867, t=18.37$, $p<.001)$ and $77.5 \%$ of the variance in the dependent variable (psychological adjustment) was caused by predictor variable i.e. self-esteem $(R 2=0.775, F(98)=337.6, p<.001)$.

\section{CONCLUSION:}

Amputation badly disturbs the psychological state of an amputee and an amputee's self-esteem is an important coping tool and has a direct relation with better psychological adjustment to limb loss.

KEYWORDS: Amputation, Acquired, Psychological, Self-Esteem, Psychosocial, Adjustment, Depression, Anxiety

How to cite this article:

Ali S, Waqar M, Anwar M, Zahid M, Satar A, Arif M. Self - Esteem as a Predictor of Psychological Adjustment to Limb Loss: A Case Study of Acquired Limb Amputation. J Gandhara Med Dent Sci. 2021;8(3): 53-59

DOI: https://doi.org/10.37762/jgmds.8-3.196 


\section{Correspondence}

${ }^{5}$ Abdul Satar, Head of Department, Orthopedics and Spine unit. Hayatabad Medical Complex, Peshawar Cell\# 0333-9239887

Email:satardr@yahoo.com

${ }^{1}$ Department of Human Development \& Family Studies College of Home Economics, Peshawar

${ }^{2}$ Specialist Registrar, Department of Orthopedics and Spine unit. Hayatabad Medical Complex, Peshawar ${ }^{3}$ Department of Human Development \&Family Studies, College of Home Economics, Peshawar

${ }^{4}$ Assistant Professor, Department of Orthopedics and Spine unit. Hayatabad Medical Complex, Peshawar ${ }^{6}$ Professor, Department of Orthopedics and Spine unit. Hayatabad Medical Complex, Peshawar

\section{INTRODUCTION:}

Amputation or loss of body parts is a traumatic life changing experience and such surgeries are usually done as a treatment strategy for the diseased or injured limb. Even though this surgery is usually performed as a life-saving measure, but still it is a highly devastating and horrible experience in a person's life ${ }^{1}$. Research revealed that amputation has proven to have alarming psychosocial consequences. It not only causes major disfigurement of body and restricts physical movements but also leads to various psychological issues as well ${ }^{2}$. In many cases the imagination of being amputated is even worse ${ }^{3}$. It not only undermines the self-confidence of an individual but also badly affects his quality of life. The feeling of being handicapped severely hurts the self-esteem of an amputee, leading to feeling of perceived pettiness and worthlessness ${ }^{4}$. Moreover, it also results in self-pity, helplessness, problems with body image and reduced selfesteem. It can rightly said that aamputation leaves permanent scars on the body and mind of amputees, which cannot be removed easily for the whole life $^{5}$. In such cases diagnosis and close monitoring is essential, as some amputees may show suicidal tendencies ${ }^{6}$. As far as the psychological adjustment to amputation is concerned, studies revealed that an individual response to some disability including amputation is intently related to their pre-existing psychosomatic reserves $^{3,6}$. Rather than developing low feelings, an amputee should consider it as a useful step towards the betterment and stabilization of physical health. People who are unable to deal with life problems or had low self-esteem would not be able to cope up with the traumatic incidence of limb loss ${ }^{6,7}$. In similar context, another study found that in case of amputation, self-esteem might serve as a basic coping tool. People with high selfesteem successfully incorporated the incidence of amputation and may discover another aspect of their being ${ }^{8}$. It is observed that almost all the research studies on amputation mainly emphasized the causative and treatment aspects of amputation and little attention was given to the eventual psychosocial problems faced by these people after limb loss ${ }^{9-11}$. The preset study accentuated that the psychological aspect is an equally critical aspect of this catastrophic event with multifaceted affects ${ }^{12}$. It aims to evaluate the psychological reaction of patients after this traumatic event and attempted to find out the nature of psychological issues faced by these sufferers. Further, the study also examined the role of positive self-esteem in the successful psychological adjustment to amputation, which eventually leads to effective dealing with this tragedy. The prime motive behind present inquiry is to put exertions for the rehabilitation of amputees and provide best support system to them.

\section{METHODOLOGY:}

This case study comprises of a sample of 100 participants both adult males and females admitted in different government and private hospitals of Peshawar district. Only patients with acquired limb amputation were included in the study. The study excludes all patients with congenital amputation, other physical disabilities or with pre-existing 
psychological problems. The data was collected from the surgical and orthopedic units of various hospitals. The participants were approached through hospital directories and were briefed about the nature and purpose of the study. Standardized scale developed by Sabir, ${ }^{13}$ was used to study the degree of patient's psychological adjustment, which consists of twenty-seven elements with five subscales. Furthermore, Rifai's Self -
Esteem scale, ${ }^{14}$ was augmented with this scale to estimate the self-esteem level of amputees. This scale also has four subscales for measuring self-esteem along four dimensions. Demographic datasheet was also used to collect demographic data such as age, gender, socio-economic level, educational background, and description of the incidence happened.

\section{RESULTS:}

Table 1: Scores of Psychological Adjustment Scale, Self-Esteem Scale and Subscales ( $N=100)$

\begin{tabular}{|c|c|c|c|c|c|c|c|c|c|c|}
\hline & Scale and Subscales & Range & Min & Max & Mean & SD & Var & Skew & Items & A \\
\hline & Psychological Adjustment & 67 & 59 & 126 & 96.7 & 18.1 & 329 & -.01 & 27 & .816 \\
\hline 1 & Perception of Reality & 11 & 9 & 20 & 15.4 & 2.9 & 8.66 & -.27 & 4 & .639 \\
\hline 2 & Ability to Cope with Stress & 16 & 12 & 28 & 20.3 & 4.2 & 17.87 & .25 & 6 & .934 \\
\hline 3 & Positive Self-Image & 23 & 11 & 34 & 24.8 & 6.2 & 39.01 & -.46 & 7 & .789 \\
\hline 4 & Ability to Express Emotions & 15 & 15 & 30 & 22.2 & 3.6 & 13.52 & .07 & 6 & .908 \\
\hline 5 & Interpersonal Relationships & 11 & 9 & 20 & 15.3 & 2.8 & 8.03 & -.19 & 4 & .823 \\
\hline 3 & Self Esteem Scale & 80 & 16 & 96 & 69.78 & 14.40 & 207.4 & -.34 & 29 & .712 \\
\hline 2 & $\begin{array}{c}\text { Self Acceptance } \\
\text { Self Competence }\end{array}$ & 29 & 23 & 52 & 39.35 & 6.256 & 39.13 & -.12 & 4 & .707 \\
\hline 4 & Academic Self Competence & 18 & 0 & 18 & 9.44 & 5.157 & 26.59 & -1.7 & 6 & .752 \\
\hline
\end{tabular}

Table 2: Mean, Standard Deviation and t-Value of Psychological Adjustment and Self Esteem

\begin{tabular}{|c|c|c|c|c|c|c|c|c|}
\hline \multirow[t]{2}{*}{ Variable } & \multicolumn{2}{|c|}{$\begin{array}{c}\text { Female } \\
n=20\end{array}$} & \multicolumn{2}{|c|}{$\begin{array}{l}\text { Male } \\
n=80\end{array}$} & \multirow[t]{2}{*}{$t(98)$} & \multicolumn{2}{|c|}{$95 \% \mathrm{Cl}$} & \multirow[t]{2}{*}{ Cohen's d } \\
\hline & Mean & $S D$ & Mean & $S D$ & & LL & UL & \\
\hline SES & 86.2 & 4.99 & 62.4 & 17.43 & $-6.03^{\star * \star}$ & -31.69 & -16.00 & 1.8 \\
\hline PAS & 121.2 & 3.54 & 90.6 & 14.85 & $-9.09^{* * *}$ & -37.18 & -23.86 & 2.85 \\
\hline
\end{tabular}

${ }^{* * *} p<.001$ 
Table 3: Variance of Psychological Adjustment, Self-Esteem and Age Groups

\begin{tabular}{|c|c|c|c|c|c|c|c|c|}
\hline Variable & \multicolumn{2}{|c|}{$\begin{array}{c}\text { Group 1 } \\
\mathbf{n = 3 4} \\
\mathbf{2 0 - 2 9} \text { years }\end{array}$} & \multicolumn{2}{|c|}{$\begin{array}{c}\text { Group 2 } \\
\mathbf{n = 3 6} \\
\mathbf{3 0 - 4 0} \text { years }\end{array}$} & \multicolumn{2}{|c|}{$\begin{array}{c}\text { Group 3 } \\
\mathbf{n = 3 0} \\
\mathbf{4 9 - 6 0} \text { years }\end{array}$} & $\mathbf{F}$ (97) & i-j \\
\hline Mean & SD & Mean & SD & Mean & SD & & \\
\hline SES & 54.73 & 16.06 & 66.86 & 17.61 & 81.63 & 9.64 & $25.35^{\text {** }}$ & $1<2<3$ \\
\hline PAS & 84.94 & 13.39 & 94.22 & 17.35 & 113.26 & 10.10 & $32.85^{\star * *}$ & $1<2<3$ \\
\hline
\end{tabular}

$* * * p<.001$

Table 4: Regression Analysis for Self-Esteem Predicting Psychological Adjustment

\begin{tabular}{|l|l|l|l|l|l|}
\hline Model & B & Std.Error & Beta & t & P \\
\hline Constant & 38.55 & 3.28 & & $11.73^{* * *}$ & .000 \\
\hline SES & 0.867 & 0.047 & 0.880 & $18.37^{\star * *}$ & .000 \\
\hline
\end{tabular}

$\mathrm{R} 2=0.775$, Adjusted R2=0.773, F (98) $=337.6, p<.001$

\section{DISCUSSION:}

The rate of amputation has increased worldwide due to increasing road traffic accidents, vascular diseases, diabetes, gunshot injuries, terrorist attacks and earthquakes ${ }^{15},{ }^{16}$. Such events cause different types of disabilities including amputations $^{17,18}$. Thus keeping in view the mounting rate of limb losses or amputation, the researcher attempted to tackle this sensitive aspect of human life. Amputation or loss of any limb limits physical functions of body, which also disturbed the psychological state of a person, resulting in exhibition of unusual psychosocial symptoms ${ }^{7,12,18}$.

Results of our study revealed that nearly all the amputees showed symptoms of psychological maladjustment. It was found that the physical restriction of amputation and feeling of helplessness and dependency ultimately leads to the development of negative thoughts about one self ${ }^{19,20}$. The person starts to feel useless, undeserving and miserable which consequently results in negative or low self-esteem. Previous studies on psychological aspect of amputation also showed similar findings ${ }^{21}$. Some common reactions found were severe anxiety, frustration, anger, helplessness, suicidal tendency, low self-esteem and depression ${ }^{22-24}$. Gender is an important socio demographic factor, which may influence adjustment to amputation. Literature stated that in case of acquired amputation, females displayed more severe psychological symptoms and have dropped level of selfesteem as equated to males ${ }^{25}$. In this respect, results of our study revealed that males scored less then females on both scales of self-esteem and psychological adjustment. Age at the onset of limb loss is also an important demographic factor in the process of adjustment. An investigation reported that young amputees exhibit more severe signs of psychological maladjustment as compared to older amputees ${ }^{26}$. Our study also verified these findings and result of the current analyses indicated that majority of young amputee's had lowered self-esteem and greater adjustment issues ${ }^{27,28}$. Current study further demonstrated that self-esteem is an important predictor of adjustment to limb loss and it has a direct relation with better psychological adjustment. It was found that an amputee level of psychological adjustment is increased or decreased by their level of self-esteem, which implies that 
higher the level of self-esteem, higher will be rate of psychological adjustment. This comes in agreement with one other study which states that amputee with positive self-esteem admits the fact that he is being challenged with a mishap in his life and it should be treated in the same way like other life challenges ${ }^{21,28}$. They are self-assured that they still have enough strength, talents and abilities to live a normal, productive and happy life. This assurance makes the adjustment process much easier and quicker $^{29}$. In such cases the role of family and society is very important in rebuilding their self-confidence and self-worth. These findings are also supported by a metaanalysis study which revealed that social support affects levels of hopefulness and self-esteem, which in turns decreases the level of depression and increases the level of psychological adjustment ${ }^{30}$. Furthermore, problematic support is linked with increased level of psychosocial adjustment issues. High level of self-esteem contributes to successful adjustment to amputation and help in the healing process. As a result, an amputee may overcome the harmful aspects of this heart-rending experience and efficaciously attains normal and healthy life.

\section{CONCLUSION:}

Amputation badly disturbs the psychological condition of a person involved. It is inferred that self-esteem is an important coping tool and has a direct relation with better psychological adjustment. Amputee's with good self-esteem considered amputation a life saving decision and crucial for their physical health. Acceptance of this fact helps them to develop feelings and determination that they are still capable enough to manage their life affairs and this makes the adjustment process much easier and quicker.

CONFLICT OF INTEREST: None

FUNDING SOURCES: None

\section{REFERENCES:}

1. Mckechnie PS, John A. Anxiety and depression following traumatic limb amputation: a systematic review. Injury. 2014;45:1859-66.

2. Bennett J. Limb loss: the unspoken psychological aspect. J Vasc Nurs. 2016;34(4):127-66.

3. Sahu A, Sagar R, Sarkar S, Sagar S. Psychological effects of amputation: a review of studies from India. Ind Psychiatry J. 2016;25(1):4-10.

4. Kearns NT, Jackson WT, Elliott TR, Ryan T, Armstrong TW. Differences in level of upper limb loss on functional impairment, psychological well-being, and substance use. Rehabil Psychol. 2018;63(1):141.

5. Falgares G, Lo Gioco A, Verrocchio MC, Marchetti D. Anxiety and depression among adult amputees: the role of attachment insecurity, coping strategies and social support. Psychol Health Med. 2019;24(3):28193.

6. Pedras S, Vilhena E, Carvalho R, Pereira MG. Psychosocial adjustment to a lower limb amputation ten months after surgery. Rehabil Psychol. 2018;63(3):418.

7. Jauregui JJ, Nadarajah V, Munn J, Pivec R, Kapadia BH, Lerman DM, et al. Limb salvage versus amputation in conventional appendicular osteosarcoma: a systematic review. Indian J Surg Oncol. 2018;9(2):23240.

8. Kuret Z, Burger H, Vidmar G, Maver $\mathrm{T}$. Adjustment to finger amputation and silicone finger prosthesis use. Disabil Rehabil. 2019;41(11):1307-12.

9. Srivastava K, Saldanha D. A study of psychological correlates after amputation. Med J Armed Forces India. 2010;66(4):367-73.

10. Neil MJ. Pain after amputation. BJA Educ. 2016;16(3):107-12. 
11. Moxey PW, Gogalniceanu P, Hinchliffe RJ, Loftus IM, Jones $\mathrm{KJ}$, Thompson MM, et al. Lower extremity amputations: a review of global variability in incidence. Diabetic Med. 2011;28(10):1144-53.

12. Ajibade A, Akinniyi OT, Okoye CS. Indications and complications of major limb amputations in Kano, Nigeria. Ghana Med J. 2013;47(4):185-8.

13. Sabir F. Psychological adjustment scale [thesis]. Islamabad: National Institute of Psychology, Quaid-i-Azam University; 1999.

14. Rifai F. Development and validation of a self-esteem scale [dissertation]. Islamabad: Quaid-i-Azam University; 1999.

15. Jensen MP, Moore MR, Bockow TB, Ehde DM, Engel JM. Psychosocial factors and adjustment to chronic pain in persons with physical disabilities: a systematic review. Arch Phys Med Rehabil. 2011;92(1):14660.

16. Gil S, Fernandez-Pineda I, Rao B, Neel MD, Baker JN, Wu H, et al. Role of amputation in improving mobility, pain outcomes, and emotional and psychological well-being in children with metastatic osteosarcoma. Am J Hospice Palliative Med. 2019;36(2):105-10.

17. Pérez MD, Chines C, García AJ, Sousa D, Fernández FJ, MarcelinoRodríguez I, et al. Major amputations in type 2 diabetes between 2001 and 2015 in Spain: regional differences. BMC Public Health. 2020;20(1):1-8.

18. Ahmad A, Ashfaq O, Akhtar N, Rana T, Gul M. Causes of lower limb amputation in patients registered at Pakistan institute of prosthetic and orthotic sciences Peshawar-Pakistan. Khyber Med Univ J. 2019;11(1):41-4.

19. Soomro N, Bibi R, Ahmed SI, Kamran B, Minhas MA, Siddiqui KY.
Epidemiology of amputation; low resource community: Sindh Province, Pakistan. Prof Med J. 2013;20(2):261-5.

20. Solgajová A, Sollár T, Vörösová G. Gender, age and proactive coping as predictors of coping in patients with limb amputation. Kontakt. 2015;17(2): 67-72.

21. Sarvestani A, Azam AT. Amputation: a ten-year survey. Trauma Mon. 2013;18(3):126-9.

22. Cater JK. Traumatic amputation: psychosocial adjustment of six army women to loss of one or more limbs. J Rehabil Res Dev. 2012;49(10):144356.

23. Uustal H. In: Lower limb amputation, rehabilitation, and prosthetic restoration. Current Diagnosis and Treatment: Physical Medicine and Rehabilitation. Maitin IB, Cruz E, editors. New York: McGraw-Hill Education; 2015.

24. Muzaffar N, Mansoor I, Hafeez A, Margoob M. Psychiatric comorbidity in amputees with average sociodemographic status and the role of theologic and family support in a conflict zone. Australas J Disaster Trauma Stud. 2012;2012(1):31-8.

25. Washington J. The relations among psychological and demographic factors in individuals with lower limb amputation [thesis]. Hartford, CT: Trinity College; 2013.

26. Pedras S, Carvalho R, Pereira MG. A predictive model of anxiety and depression symptoms after a lower limb amputation. Disabil Health J. 2018;11(1):79-85.

27. Sahu A, Gupta R, Sagar S, Kumar M, Sagar R. A study of psychiatric comorbidity after traumatic limb amputation: a neglected entity. Ind Psychiatry J. 2017;26(2):228.

28. Herrera-Moreno D, Carvajal-Ovalle D, 
Cueva-Nuñez MA, Acevedo C, Riveros-Munévar $\mathrm{F}$, Camacho $\mathrm{K}$, et al. Body image, perceived stress, and resilience in military amputees of the internal armed conflict in Colombia. Int J Psychol Res. 2018;11(2):56-62.

29. Chang CW, Yuan R, Chen JK. Social support and depression among Chinese adolescents: the mediating roles of self-esteem and self-efficacy. Child Youth Serv Review. 2018;88:128-34.

30. Topcu G, Griffiths H, Bale C, Trigg E, Clarke S, Potter KJ, et al. Psychosocial adjustment to multiple sclerosis diagnosis: a meta-review of systematic reviews. Clin Psychol Rev. 2020;82:101923.

\section{CONTRIBUTORS}

1. Shaista Ali - Concept \& Design; Data Acquisition; Data Analysis/Interpretation; Drafting Manuscript; Critical Revision; Supervision

2. Muhammad Waqar - Data Analysis/Interpretation; Drafting Manuscript; Critical Revision; Supervision; Final Approval

3. Musarrat Anwar - Concept \& Design; Data Acquisition; Supervision

4. Muhammad Zahid - Concept \& Design; Data Acquisition; Critical Revision; Supervision; Final Approval

5. Abdul Satar - Concept \& Design; Data Analysis/Interpretation; Drafting Manuscript; Critical Revision; Supervision; Final Approval

6. Muhammad Arif - Data Acquisition; Data Analysis/Interpretation; Supervision 